Article

\title{
The Quest for an Adequate Test: Justifying the Sustainable City as an Order of Worth
}

\author{
Meg Holden \\ Urban Studies Program and Department of Geography, Simon Fraser University, 515 W. Hastings St., \\ Vancouver, BC V6B 5K3, Canada; mholden@sfu.ca
}

Received: 10 May 2020; Accepted: 4 June 2020; Published: 8 June 2020

\begin{abstract}
The sustainable city represents an ideal of good and just living that has inspired urban development work for at least 25 years. While criticized by many for its scientific, social and political vagueness, the concept of the sustainable city has nonetheless continued to frame material and political efforts in urban redevelopment. From a perspective grounded in the pragmatic sociology of critique, this article takes this phenomenon as evidence of an international movement to generate not just political pronouncements or technical fixes, but a new order of worth, from the concept of the sustainable city. After presenting the pragmatic sociology of critique and the application of this body of social research as it pertains to better understanding sustainable urban development, we reflect on the factors that challenge the acceptance of the sustainable city as an order of worth, or as a mode and manner of justifying significant decisions in the public domain, recognizable and understandable to a majority. For efforts to create the sustainable city to justify themselves, socioculturally, in this way, the work demands a clear test of worthiness. This article illustrates the search for an adequate test through a review of two distinct efforts to generate new systems of assessment for sustainable building projects, and points out the contrasting nature of these two tests: one which aims to be accessible to thoroughgoing public debate fit to transform a context toward a political discourse of urban sustainability as well-being; the other that interprets the need for a test as affirmation of expertise related to the unfolding climate emergency.
\end{abstract}

Keywords: sustainable city; pragmatic sociology of critique; sustainability assessment; sustainable neighbourhoods; urban redevelopment

\section{Introduction: What Does It Mean to Justify the Sustainable City?}

In the important project to generate new ways of living in cities that are less harmful and more just, the concept and practices of sustainable development have much to offer. Many justifications have been mobilized to understand and explain the value of urban life, over time. Given the politically vague terms in which goals of sustainability are positioned, the legitimacy of a host of justifications of the city for changes in the direction of sustainable development is imprecise and "up for grabs" [1].

Within many justifications of sustainable urbanism, the principle of subsidiarity is often invoked; that is, that the soundest decisions are made at the scale local to those most directly affected by the decision. Along with this is the notion that the cynicism, lack of trust, and anti-social behaviour exhibited by citizens with respect to the choices made by economic and political leaders are tempered at the local scale, where the clear and positive results of local engagement are self-evident [2]. Cities act, as proclaimed by mayors opting to join the $\mathrm{C} 40$ cities initiative for carbon-neutral cities and so to make "a commitment to work collaboratively to address one of the greatest economic, social and environmental challenges of our time" [3]. Neighbourhoods, by extension, may act even quicker: "Neighborhoods provide a uniquely valuable scale to introduce and accelerate investments that can achieve profound improvements in equity, resilience, and climate protection" [4]. 
At the neighbourhood scale, the sustainable ideal becomes slightly more clearly defined. The ideal of the sustainable neighbourhood is a justification of the good to be done in remaking cities as local, parochial places in which people can dig in to local life without sacrificing their networked connections to global circuits of economy, people, knowledge and culture, where environmentally-sound and health-promoting choices are built into the design of the structures and landscapes on offer, and where equitably-distributed power can shine out and scale up from a place of authenticity and just action. The localized sustainable neighbourhood ideal presents a picture of genuine lives being authentically lived, and transformative changes toward justice and environmental quality falling into place from this choice. This is possible by maintaining a modest circumference of life that respects durable physical limits to how far people are willing and able to travel on a daily basis and that asserts people's rights to occupy public spaces and invites them to their common home in the city.

This article recognizes the powerful appeal of the sustainable city and sustainable neighbourhood within it. In particular, we acknowledge the significant work ongoing in many countries of the world to design and build model sustainable neighbourhoods that offer new opportunities to realize the sustainable ideal. These efforts are not delivering on their promises. We struggle to find credible arguments for movement of any recognized dimensions of sustainability in the direction of the ideal. Many credible accounts exist of trends that are clearly worsening: in urban inequality, unjust levels and distribution of hardship, troubling trends in climate change, environmental damage and consumption, ill health, hunger, worsening levels of social trust, and more [5-9]. While we do not claim here that the work to build sustainable cities and neighbourhoods is responsible for any of these negative trends, it is ostensibly not helping matters, either.

Drawing upon the framework for understanding and approach to action defined by the pragmatic sociology of critique, this article asks whether the way we justify sustainable development in the city is partly to blame for this lack of results. We will focus on the case of the proliferation of both model sustainable neighbourhoods, presented elsewhere, and the frameworks that have concurrently been put in place to measure, assess, and certify their results in terms of sustainability $[10,11]$. The work of certifying, indicating and assessing model sustainable neighbourhoods is significant, and also demonstrates recognition among those promoting the application of model sustainable neighbourhoods that their work needs a new reference, a new test of value. The pragmatic sociology of critique opens up an examination of what these assessment systems are up to, from the perspective of what is needed in order to advance a new normative idea about what is good and right in the social world that people share in common and that will withstand the objections of those who hold to pre-existing understandings of normative social value. Drawing together threads of the debate in the pragmatic scholarship of sustainable neighbourhoods from francophone and anglophone contexts, along with two cases of novel attempts at neighbourhood assessment systems, this article seeks to provide new answers to the question of what it means, and what it takes, to justify a sustainable urban neighbourhood.

Neighbourhood-scale planning has been a fascination of the urban planning profession since before it was a profession, and has attracted utopian views and perspectives on optimizing life conditions [12]. The work of putting sustainable neighbourhoods in place belongs principally to urbanists, planners, architects, elected officials, developers, citizens, and advocacy groups. What seems to accompany this in almost all cases is the work of a set of professionals and researchers, a group that overlaps with those responsible for creating the neighbourhoods themselves. These efforts have themselves given rise to a series of new tests to assess, indicate, label and certify sustainable aspects of these projects, often with an attempt to standardize these efforts nationally and internationally [13]. These frameworks for assessment themselves may come close to outnumbering the completed model sustainable neighbourhoods.

This is no accident: the certification is needed in order to create the social platform from which we can stand, point a finger, and claim with any confidence that, there, is a green city, sustainable and just. The platform provides the reference scenario without which none of our experiments can be assessed with any sense of adequacy and comparability and without which all these experiments are 
liable to critique as having failed to measure up to their potential, or to have not merited the extra cost or effort of their difference from the status quo. From the perspective of the pragmatic sociology of critique, the world of action on the sustainable city is a world of competing justifications of the good city [14]. In order to rationalize and prove the value of work to bring the sustainable city into being, new means and arguments for the good city need to be created, tested, and accepted as worthy. This would constitute a new order of worth, fit to meet new demands for action to achieve better cities in the future.

The work to build new pieces of city in the new manner and the work of generating standards and certifications for built products are important. However, the pursuit of these standards and reference frameworks is often conducted at cross-purposes to the task of actually devising a common sense, across contexts, of what it would mean to live differently in a model sustainable neighbourhood or district. I argue here that the quest to generate unifying certifications and standards for sustainable cities overlooks and avoids the crucial task of justifying and normalizing this change-making work in particular contexts and at particular political moments that are held in common by the actors concerned. It is precisely these positions of what is and is not justifiable in the given contexts of would-be sustainable cities that need to be articulated and argued about for these urban transformations to make a difference. Yet not all assessments are created with this notion of a test in mind.

While the normative dimension of cities shifts to reflect societal ideals for sustainable development, the work of creating new standards, certifying and labelling systems, assessment and indicator protocols can be thought of as the work to steady this normative shift with new reference materials. This latter work provides the material tests for the aspirational, normative cloud of dreams about the sustainable city. As I will present next, this work of generating, publicizing, and repeating tests is critical to the generation of a new order of worth, a new mode of justifying normative social reality qua sustainability. However, I will also make the argument that these tests need not abandon the normative domain of debate in order to be effectively generated and used for this purpose. Instead of hiding behind a guise of objectivity "beyond debate," reference frameworks for sustainable developments need explicitly to engage with normative claims in order for them to be discussed, treated to the test of engaged dialogue among people who are seeking to build and live in new sustainable cities. Only this can pragmatically ensure that we get the tests right, and ensure that these tests have social value fit to the claim that sustainable development is making upon the social world.

As a non-trivial example, much of the normative debate about the value of model sustainable neighbourhoods in cities today surrounds the question of the extent to which these are inclusionary or exclusionary of poor and marginalized people. Assessment systems for sustainable development do not offer a sufficient test on this question, although some offer measures such as the percent of social or subsidized housing available for lower-income populations. Normative justifications of sustainable cities are also unhelpful on this point; we find a general argument that all people, indeed all generations, must be served by development that is sustainable, but little assistance in understanding how or how much levelling of inequities needs to occur, or how closely to one another rich and poor ought to live. A given sustainable neighbourhood, then, can meet a given certification test of, for example, including $25 \%$ social housing, but if this point remains normatively unjustified within the framework of sustainable development overall, the achievement of this test remains as a box to tick on a checklist of many, rather than an element essential to achieve in the overall normatively sustainable city.

The pre-eminent way in which a test of a sustainable neighbourhood is conducted is via an indicator-based assessment, certification or labelling system. We do not make the claim here that reference measurement and assessment systems for sustainable development are not fit to incorporate normative debate. On the contrary, the evolution of numerous prominent reference systems has been in this direction: the shift in the LEED (Leadership in Energy and Environmental Design) family of assessment systems toward inclusion of regional credits, for example, as well as post-occupancy evaluations; the process-oriented and collaborative approach within the EcoDistricts Protocol and the Step 4 Evaluation system within the French écoquartier program are notable. However, there remains 
a general expectation among those who trade in assessment systems that these systems can settle debate, at some point. To the extent that this expectation holds for the assessment systems, and the assessments themselves remain the primary test of sustainability outcomes of these districts, they do not advance the layering of sustainable cities into the ways available to people to generate credible arguments for belief and action in the social world. For this latter move to happen, what is needed is a commitment that the debate needs to remain normatively-active to become a culturally-relevant test of sustainable cities.

\section{Justifying the Sustainable Urbane: The Contribution of the Pragmatic Sociology of Critique}

As set out originally by Boltanski and Thévenot [15], the pragmatic sociology of critique is an approach to understanding the lifeworld through the initial proposition that actors work to 'justify' their own positions and denounce those taken by others when they disagree. This approach represents a more dynamic understanding of the social world than the structural frameworks that these two sociologists had been handed by their mentor, Pierre Bourdieu. A critically pragmatic interpretation thus seeks to "[draw] out the principles of legitimate order that [justifications] contain," (p. 14) rather than assuming that the structure of social order is fixed in some equilibrium model emanating from power and domination. Boltanski and Thévenot build upon a set of axiomatic assertions that they view as dominant, justifiable orders of worthiness in contemporary Western (French) society. These six canonical orders-industrial, opinion, inspired, civic, domestic, and market—constitute forms for describing, classifying, thematicizing and analyzing reality in ways that are commonly relatable. These orders of worth or models of justification-two alternate translations of the French modèles de cités-"propose a general formulation-applicable to everyone in all situations-that validates the play of customs, procedures, settlements or rules applied locally," (p. 71). They are the source of the justifications that people draw upon implicitly when they need to craft arguments about what really matters in a given situation. Importantly, these orders of worth were not put forward as universal but as relatively stable and recognizable, with their own particular grammar when arguments were made in their favour, although these grammars could be bent and shaped over the medium term through the force of public argument and action in the social world. Pointing out their existence and structure shows not only that they are dominant ways of crafting common understandings of the social world but also that each is highly debatable, each draws out critical moments at which their validity is tested in terms that matter in real decision making contexts $[16,17]$.

Boltanski and Thévenot thus conceive of their work as "grammarians" who purposefully facilitate the construction of "social bonds" by offering classifying explanations of the play of different competing models of "legitimate order" [15], (p. 19). They explain the value added by their approach to understanding social worlds that is particularly relevant to finding possibilities for social change:

"When one is attentive to the unfolding of disputes, one sees that they are limited neither to a direct expression of interests nor to an anarchic and endless confrontation between heterogeneous worldviews clashing in a dialogue of the deaf. On the contrary, the way disputes develop, when violence is avoided, brings to light powerful constraints in the search for well-founded arguments based on solid proofs [such as those grammar-like ready-mades that public intellectuals supply], a search that manifests efforts toward convergence at the very heart of disagreement [15]." (p. 13)

In this way of interpreting social reality, each vocal actor should be treated as holding an equal opportunity to justify a decision or action, but each must at the same time be accountable to engage in disputing the merit of other offered justifications, if so called. The justifiability of the claim depends crucially upon who is willing to justify it, and how, and what challenges are mounted. This understanding of a given reality incorporates differing levels of worthiness among actors and objects in a context-specific way. It sets up an expectation of finding a sequence of critiques the balance and nature of which will change over time. This balance of critiques, once brought into the realm 
of dialogue and debate, challenges actors who seek to have a meaningful voice in public matters to work to reconcile their disagreements by distancing themselves from some critiques and incorporating others into their identity and operations. This challenge is felt more keenly by organizations, and by organizations that depend upon some perception of consistency and public acceptability of their structures and their functions. A city or neighbourhood itself, in this context, can be considered a kind of super-organization, in which this interplay of justification, compromise, and test is very active [17].

Taken together, it is some actors' positions-analyzable in terms of ideas and objects successfully mobilized - that shape the outcome of a dispute and thus, the structure of social reality in a given context. Actors mobilize not only distinct understandings (epistemologies) but, simultaneously, different experiences of the world (ontologies) when they enter into public debate. As such, the critical pragmatic approach to understanding social worlds weaves together Foucauldian governmentality theory's power-laden worldview with what Gilles Deleuze and Felix Guattari [18] and later, Bruno Latour [19] saw as assemblages or John Law called the sociotechnical order [20]. The presence of a plurality of different potential 'orderings' of the world suggests the possibility of uncovering, and mobilizing, different and competing 'models of justice' or 'orders of justification' which could put the future on a very different development path than the one it may be on today.

In these terms, subjective action and policy oriented towards a particular direction of social change, such as sustainable development, achieving individual and collective well-being harmonizes society, creating "a principle of economy that balances access to the state of worthiness against sacrifice for the common good" [15], p. 72.

The question of how to understand and act in the face of the challenge of sustainable development has been considered within the pragmatic sociology of critique since the early 1990s, beginning with papers by Barbier [21] and Lafaye and Thévenot [22]. This article contributes to this effort and calls for more conceptual and empirical study of this significant question. The task, as interpreted within the pragmatic sociology of critique, is to construct a hegemonic grammar demarcating the instrumentalization of a politics of sustainable development, in much the same way that "economic efficiency" is an argument with a hegemonic character that can be leveled in various political and discourse arguments, with a transparency and predictability in terms of political consequences. The first task of analysis of how this challenging politics is engaged is first to understand the different forms taken by sustainable development as a critique of all other orders of justification. The second task is to help social and political actors grasp that which is critiqued, at what moments, how and to what envisioned ends, in order to chart a politically feasible path toward sustainable development.

Theorists working within the pragmatic sociology of critique have been openly cognizant of the possibility of generating new orders of worth over time, with a process of compromises, tests, and new justifications that emerge from public debate into policy, law, and social structures. Indeed, there is an argument within the theory that, whereas most social critique can be characterized in terms of an imbalance of weight given to a market order of worth compared to others, it is instead the regular deployment of a range of orders of worth and the conduct of tests for each that sets "the course to long-term viability" of a city [23]. For example, the classical industrial order of worth which values efficient, mass production of goods, is tested by revelations of induced demand that means waste actually increases when goods are made efficiently. Pointing out this paradox opens the door to understand what new values undergird the shift in understanding. Most notably, Boltanski and Chiapello [24] made a persuasive case for the rise of a new "projective" order of worth in the 1990s as a necessary shift of market order justification that incorporates the crises of capitalism occurring at the time. Further work on the process of generating new orders of worth has tended toward the expectation that much more often than a new order being generated, compromises between existing orders are struck in a temporary and fragile way, that often break down as the actors in play revert back in time to pre-existing ways of justifying their views and actions.

The question of whether or not a "green" or "sustainable development" order of worth exists in society at large has been treated most within the French literature, including by [25-32]. This article 
should be seen as seeking to contribute to this work, and also as the work of an "unfaithful follower" [33] in the sense that my approach is not one of systematic urban sociology. Boissonade [31] refines his position on the question of whether the practice and thought around sustainable development has developed to a sufficient extent to be characterized as a new order of justification, alongside the tried-and-true justifications of efficiency in industrial pursuits, inspiration in creative pursuits, and loyalty in domestic pursuits. He concludes in the case of French social and political contexts that the idea of sustainable development takes the form of an instrument of governance rather than a more basic social norm. He goes further to suggest that the work to internalize sustainable development within French culture tends to make the application of the concept itself more fragile, by raising tests of the model without being able to reconcile or incorporate them into the dominant culture. In this way, the grammar of sustainable development as articulated and performed across sectors is in a process of more or less continuous renewal without either meaningfully deepening in cultural relevance or expanding in its cultural meaning in order to find anchor. Godard [28] and Centemeri [30] also doubt that sustainable development can constitute a new and enduring order of justification, given the extent and movement of controversies and debate in this area.

Notably among these French scholars, Boissonade considers the case of the French écoquartier or ecodistricts program in order to interrogate the scene of debate for evidence of development of a new sustainability order of worth. Within the global race to create model sustainable neighbourhoods, France has been a leader, announcing its national écoquartier development program in 2009 with continuous efforts made since. This makes the results of this work some of the most widespread and complex super-organizational objects that the concept of sustainable development has created.

To Boissonade [31], the dynamic of evading tests by justification jumping impedes the solidification of sustainable development as an order of worth in at least two different ways. First, the sustainable development discourse has a tendency to consume its own critique. The discourse of sustainable development puts forward a series of tests that seem to be in limitless supply-from green economy, to energy transition, to green growth, to carbon neutral, and on. However, these do not all add up to anything like a coherent and internally consistent whole concept of the good life. Importantly, within the structure of the pragmatic sociology of critique, this string of concepts that each tackle a piece of the sustainable development puzzle does not constitute or suggest a single clear test procedure by which to justify an action of sustainable development [28]. The problem is that the discourse discards each new test as soon as a contest arises, and moves on to the next, without resolution, while argument and resolution are necessary for the internalization of a new order of justification in a cultural context. The tendency of the sustainable development discourse to consume its own critiques prevents the establishment and operationalization of a test, although this is crucial for the formalization of an order of worth that is in some way homogenous and culturally recognizable.

Also problematic in this dynamic is that the seeming inability of sustainable development discourse to confront and internalize tests raised about its consistency renders the enterprise of sustainable development open to the critique that it is not, in fact, open to argument and critique at all. This is an impossible position to hold, if we hold to the idea of critique being a core capacity of free and democratic society. The facts that sustainable development appears constantly to be brought into confrontation with a variety of critiques that it only responds to in a piecemeal way and that these piecemeal answers are sometimes contradictory with other aspects of the doctrine, render the whole enterprise fragile and less able to anticipate the arguments and objections likely to arise next. At the same time, sustainable development continues to be mobilized in a host of diverse organizations and practices, including some that are critical, grassroots alternatives to hegemonic society. These latter interpretations of sustainable development can be expected to resist efforts to generalize the work of sustainable development under a single test procedure, whether that test is articulated as a metric like the concentration of carbon in the atmosphere, an ecological footprint, fair earth share, or otherwise. Critical, grassroots and alternative practices and formulations of sustainable development work will, by contrast with the work of more mainstream articulations, marginalize their own work 
by offering up a sustainable development compromise that is acceptable within the mainstream cultural understanding of what is politically possible. At the same time as the work of interpreting critique in this pragmatic way serves as an "interpretive tool for experiences," it comes up against the irreducibility of experiences that gets in the way of treating any given grammar of justification as pure and unadulterated by compromise [31].

Considering its application in France in particular, Boissonade [31] summarizes five core denunciations of sustainable development as an order of worth. Each of these denunciations represents a critique to which initiatives in sustainable development are subjected in the city, and to which actors do mount rebuttals, but that are often considered piecemeal, insufficient, or to generate new questions about authenticity and reliability. Extrapolating from and building upon this, Table 1 demonstrates how each of the seven accepted orders of worth generate denunciations of sustainable development as an order of worth, thus also calling into question the notion that there is anything sufficiently original and different about the invocation of sustainable development as a value to merit its inclusion as a new and unique order of worth.

Table 1. Denunciations of sustainable development from the argumentative perspective of the other core orders of worth (adapted from [31]).

\begin{tabular}{lc}
\hline Denunciations of Sustainable Development as a Unique Order of Worth & Accepted Order of Worth \\
\hline $\begin{array}{c}\text { While sustainable development purports to represent a balance between development and } \\
\text { sustainability, in practice it is the efficiency of the results that are justified and valued. }\end{array}$ & Industrial \\
\hline $\begin{array}{c}\text { Sustainable development is operationalized primarily in technical terms, ignoring the } \\
\text { significance of opinion order justifications and blind to the richness of experience. }\end{array}$ & Opinion \\
\hline $\begin{array}{l}\text { When sustainable development is justified in inspirational terms as a utopian ideal, its value is } \\
\text { indistinguishable from that of the inspired order of worth, though it falls short of the full reach } \\
\text { of inspiration as justification. }\end{array}$ & Inspired \\
\hline $\begin{array}{c}\text { Sustainable development proposes to reinvent democracy but without adequate grasp of the } \\
\text { demands of local democratic engagement as offered in the civic order of worth. }\end{array}$ & Civic \\
\hline $\begin{array}{c}\text { Sustainable development projects lead to surveillance and control of individual freedoms that } \\
\text { have been treated as cultural or private and not amenable to government control. }\end{array}$ & Domestic \\
\hline $\begin{array}{c}\text { The pursuit of sustainable development is mostly seeking green value, to capitalize "green" in } \\
\text { new markets. }\end{array}$ & Market \\
\hline $\begin{array}{l}\text { Sustainable development projects are justified insofar as they are smart and innovative, not to } \\
\text { the extent that they are sustainable per se. }\end{array}$ & Projective
\end{tabular}

This distribution of challenges to the "worthiness" of justifications of sustainable development points out the difficulty of establishing a new order of justification in a contextually- and culturally-authentic way. In diverse urban society, in democratic contexts, there is no credible way for the diversity of actors implicated in any authentic move toward sustainable development to rest upon a single and same principle of justice in understanding and operationalizing the common world. Instead, there are strong motivations for actors to seek to change the terms of debate, drawing from different orders of worth, in order to destabilize other arguments and assert new configurations and assemblages of arguments and orders. Our cities already present ample evidence of the asymmetry and imbalance among the strength of arguments for justice versus profit, restitution versus reconciliation, growth versus sustenance, for example. Rather than stick to arguing "tit for tat" using items of the same general scale and order to resolve debates, when a situation is already asymmetrical, actors seek to change the terms of the debate and the order of what is being debated as part of an approach of resymmetrization [32]. Multiple, mutually-incompatible debates about the authenticity, viability and desirability of sustainable development as a way to justify and motivate a better common future is a key case in point.

The exercise of critique is a key legitimate means of achieving justice and social change. Of course, it is untenable to assume a level playing field of critique and debate. Instead, what is manifest is the existence of many competing worlds within any given city. Some of these are fundamentally incommensurable, held in common by certain groups but rejected by others, as well as fundamentally inequitable, and embed many competing understandings of value and justifications of what makes 
these worlds livable. A core imbalance exists between those actors and groups that establish the terms of the debate and those whose suffering gives rise to debate. In many debates about the sustainability of different segments of the city, it is this dynamic that supersedes any other debate about the meaning and utility of the concept of sustainable development to reinvent the city. The most common and everyday test to which model sustainable neighbourhoods are put, around the world, is the test of how that place, and its structures and actions, works to regulate the behaviours of people who are considered most expendable [34]. Whereas Table 1 implies a sort of symmetry in the quality and strength of arguments that critique sustainable development experiments in practice, this sense of balance is misleading. In fact, these arguments and tests are shot through with power and conflict arrangements that result in clear asymmetries in the articulation and resolution, if any, of tests of the worth of sustainable development initiatives. The resolution of the issue at play is at least as likely to render situations more asymmetrical than less so.

In pointing out these asymmetries, Boissonade [31] seeks to initiate more scholarly attention to what he calls a pragmatic sociology of strengths. A focus on symmetries, asymmetries, and the exercise of power within tests could help reveal not just state of play of debate-the compromises and special arrangements made to resolve and move on from tests. In addition, this approach assists our understanding of the sense and the work of the discourse and concept of sustainable development in the power-laden and unjust city. Critical moments can be identified and dissected for the dynamics of their tests and arguments, but at the same time the critical dynamics of attempts to impose new asymmetries, or, more hopefully, symmetry between actors can be investigated. When it comes to testing sustainable development on the ground in cities, the most prominent test moment is often the production and reporting of sustainability indicators for a project or neighbourhood. Further, these tests, as will be shown in the two cases considered here, are full of asymmetries.

Lejeune and Villalba [35] ask whether sustainable development has reached the point of mainstream cultural acceptance as an order of justification within French culture. They consider a test of the green order of worth within the context of a specific instance of an urban redevelopment project that successfully applied for a label given by the French government, within the Grand Prix National des Écoquartiers. They ask whether the results of the adjudication of this prize, in 2011, are testament to the legitimization of a sustainable or green order of justification that can be meaningfully differentiated from the other kinds of criteria used to justify and reward urban development: economic progress, technical efficiency, civic participation. The écoquartier in the Union district near Lille in the north of France was developed using a discourse of social change toward sustainable development: including co-conception of projects, respecting heritage and local preferences and adoption, along with green building and design criteria. In this case, the researchers found that while winning the écoquartier label garnered local legitimacy for the project, and raised the stakes for other projects in subsequent rounds of the annual competition nationally by reference to it, there is no evidence that the project itself has pursued a path of green or sustainable urbanism. From the perspective of the project's developers, the only evidence of a justification they locate is a continuation of the typical logic of economic production - that the project should contribute to a continued growth of economic activity, such that individual consumption of economic goods and services may also continue and grow. Despite values and visions stated to the contrary, they find that exceptions were made in order to guarantee that the values of private sector actors were prioritized over other more experimental values put in place, aspirationally, for the sector as a whole.

They reach the damning conclusion, as far as the conduct of the test itself and, by extension, the prospects for social change that could stem from modelling sustainable neighbourhoods in cities, that "The Union écoquartier is an urban artefact with an economic vocation that lacks any local anchor." [35] They see the existence of the écoquartier label itself as an argument for a green order of worth without grounding in the project, whereas the innovations demonstrated in the project appealed to external recognition and labelling as something notably green or sustainable. For these researchers, a more telling test than that the neighbourhood won the prize was the fact that a resident 
collective formed with the intention of working in a concerted and participatory manner with the developer. The work of this collective, toward the specific goals of local inclusionary social and economic development, social housing, environmental justice, biodiversity, and learning from the best practices of other promising projects, was shut out by the project developers. This, although the existence of the resident collective was heralded within the project's Écoquartier label application, as evidence of the avant garde participative nature of the project. Lejeune and Villalba [35] end their study with something like a lament: if there is a green order of justification, we are still seeking the test that will bring it into discourse and thus into reality as an urban development practice. What the Union écoquartier delivered was the patina of sustainable development pursued under a business as usual approach of industrial efficiency and market logic, along with an aesthetic and technical adoption of green urbanist architecture and design.

Other researchers investigating urban sustainability within the pragmatic sociology of critique express reasons why we should expect serious non-expert engagement with the idea of sustainability as the idea takes root. Anders Blok [36] has argued for the importance to inquiry of identifying a 'green' model of justice. Blok describes how a form of "green cosmopolitan urbanism" might be seen as an important symptom of what Boltanski and Chiapello [24] defined as a new order of justice that emerged as the contradictions of capitalism forced changes to capitalism as an order of worth, in The New Spirit of Capitalism. Indeed, Blok's use of Boltanski and Chiapello's argument highlights some of the contours of an emerging compromise between green, market and networked models of justice. For Blok [37], cosmopolitan urbanism mitigates the environmental riskiness of contemporary life, where "place-based notions of 'culture' are mobilized in the urban visions of architects and engineers as resources for addressing global environmental risks, [creating] spaces of urban green cosmopolitization."

Moreover, as Blok shows, the networked or projective model of justice is readily employed in the testing of sustainable development on the ground in cities:

"Most representations of urban sustainability-as produced in-between the social worlds of urban planners, architects, city administrators, green-tech firms and community movements-are heavily invested in grammars of networking, sharing project experiences, and working towards innovative and creative green solutions. In fact, the dominant cognitive-moral format for organizing urban sustainability efforts is that of creating and circulating examples, cases and demonstration projects, cast in the language of 'best practice." [36]

Blok's 'representations of urban sustainability' characterize the work to foster livable, creative places, in which the worthy, who are able to succeed in this flexible, networked and green marketplace, can work toward their own well-being and if possible, the greater good. The appeal of sustainability as an alternative does not sit outside the market order of worth, but represents a merged compromise between market and green orders that can be considered a particular "spirit" of capitalism in a networked, green, livable place on earth. Montgomery's [38] ethnographic research in Detroit demonstrates a similar state of play in which the networked "new spirit of capitalism" draws upon the justification of the creative class approach to urban development that also embraces green and place-based strategies, while ignoring older industrial labour-based critiques of capitalism.

Pattaroni [39], drawing from research on a case of a proto-green neighbourhood experiment in Geneva, called the Grottes, take this conclusion even farther. Over the course of years in this sustainable development experiment, he witnessed the emergence of a neighbourhood space that was beyond the reach of the market, and a site for cooperative living in more justice-serving arrangements that pursued sustainable lifestyle opportunities. Later, as the city took note of the potential of this neighbourhood for inclusion within the dominant story of sustainable development innovations, new development was proposed that changed the neighbourhood while labelling it as a model of sustainable development. The change did incorporate the existing residents and many of their utopian ideas, including community cooperatives and ecological approaches. Spaces continued to exist outside the strict demands of market logic, preserving possibilities for non-market social and political interactions 
and projects, even as market value was created anew in adjacent spaces. Rather than an outright destruction of the pre-existing place and its alternative practices, the development of a "mainstream" model sustainable neighbourhood in the Grottes demonstrated a "consolidation of compromises." These compromises between the market logic of urban development and the ideals of the counterculture still present in the Grottes preserve the utopian spirit of sustainable development "but it also takes away their subversive dimension."

The critique here is not too far off the mark of what has been presented as the "just green enough" argument for how sustainable development is pursued in cities today [40]. As groups engaged the question of the best sustainable future for the Grottes, using different justifications, they called the ideal of limitless capitalist expansion into question. This engagement with compromise in itself served as critique of the subversive approach of a more radical refusal of capitalism. The compulsion of the groups to understand one another's recognizable and different logics forced a compromise on both fronts. The possibility of spaces and opportunities outside of the market order needed to be provisioned, and they were; but the "dynamics that govern the development of a well-equipped, profitable, and competitive city" also could not be denied-and they were not.

Pattaroni considered the implications of this necessary compromise, particularly acute in the city, where plans and decisions are necessarily agonistic. What they considered the fundamental urban dynamics of cities are constituted by moves taken and justified by a whole gamut of different actors, and not limited to the work of any singular powerful actor, group, or policy decree. Cities change, and city life changes, due to formal and informal processes, justified in very different ways, that interact and interplay with one another, sometimes unpredictably.

Because of these crucial urban change dynamics, these researchers drew the conclusion that the very pursuit of sustainable development in cities via measured experiments in model neighbourhoods puts the work of changing the city toward sustainability in a double bind. On the one hand, accepting life in a model sustainable neighbourhood demands relatively high levels of environmental discipline, participation, and social conviviality, compared to the baseline expectations of city living. Because these demands have an impact on liveability and sustainability that is largely unproven, at least in modern civilization, there is a demand for the use of tests. Typically, these tests are offered in the form of indicators, assessment systems, labels of authenticity and difference. While these indicator systems often take participation of different voices into consideration, the net effect tends to be reducing the spectrum of perspectives to within the scope of what does not fundamentally conflict with other operating orders of worth. On the other hand, the proliferation of these indicators has the appearance of rendering justification unnecessary, whereas the encouragement of debate and the development of new social and political justifications is precisely what is needed to generate a meaningful order of worth from the mix of practices and articulations of urban sustainable development. This ignores the city's fundamental agonism in favour of the pursuit of compromise, whereas: "some values are very difficult, even impossible, to reconcile in the real world, which forces us to make a decision, sometimes at the cost of excluding a few principles and lifestyles." [39] The unavoidable heterarchy of values is echoed by Stark [33] who points out that the heterarchy but comprehensibility of the principal statements of value within the pragmatic sociology of critique is the very means by which the creation of a common world of engagement becomes possible.

Pattaroni raises a concern about the problematic nature of this double bind for the pursuit of model sustainable neighbourhoods in the city: "despite the existence of these new institutional and architectural innovations, one must ask to what extent it is possible to replace urban conflicts with a series of "indicators," namely to transpose the different principles thus upheld with so many measurements of the city's economic, social, and environmental performance" [39]. Debate about sustainable development in the city does not become unnecessary with the use of indicators and formal assessment systems; debate in fact is the only thing that can offer sustainable development a durable and authentic place within the contextualized social and political world of the city. If this debate is externalized from the pursuit of sustainable development, the notion of sustainable development that 
is being pursued loses its utopian value, its ability to devise thoroughgoing and persuasive tests of other ways of justifying action in the city, that would justify a move for sustainability and away from a market, networked, industrial, or domestic order of worth.

This concern is commensurate with that raised by Boissonade, who concludes not so much that a green order of worth is not justifiable as a green or sustainable order of worth has yet to be convincingly justified. Even for researchers who are already convinced of the value of pursuing sustainable development, the critiques of sustainable cities are unavoidable, and demand further debate and tests in cities. These critiques come from across different orders of worth and express themselves differently in different contexts. The opportunity to address each critique in democratic debate, in context, is the opportunity to establish not merely a compromise, but a clearer public understanding of the symmetry of power between different justification approaches. It is this work of debate, at critical moments of testing between the value and strength of different varieties of justification, that offers the potential to recalibrate our understanding of the mix of active justifications of contemporary life prospects as well as utopian ideals in the city. At the same time, this work is essential and key to the ongoing project of enlivening democracy and common action toward an ideal of social change [14].

\section{Sustainability Certification Systems: Scientific Precision or Avoidance of the Tough Questions?}

The existence of multiple, unresolved tests of the green city demonstrates that the value of sustainable development has yet to be established as a clear and coherent order of worth in a given cultural context. Other research has taken up the task of unpacking and comparing the impact and value of prominent national and non-governmental sustainable development assessment systems [41-45]. Suffice to say here that an array of government and non-government entities are engaged in the work of testing sustainable developments by different means and measures. To borrow from Stark [33], the trend is a proliferation of new "valuemeters" of what should happen in these projects. In this paper, we capture a more acute instantiation of the phenomenon of the quest for an adequate and reliable test of sustainable developments by examining the work that two private design and architecture firms have done within the past two years, to make their own assertions about the test that is needed. In so doing, we help answer the call from Stark [33] for "research that examines the historical patterns and the contemporary effects of the emergence of organized competitions (sustainability rankings or "green" prizes) inside the economy." This situation speaks to the acute demand for a new test of what we are doing when we build models of sustainable development. Unlike governments and non-government entities, private design and architecture firms ought to be preoccupied by the creation of individual market value and perhaps values of industrial efficiency. Because these organizations are at home in market, projective and industrial orders of worth, they stand only to gain indirectly from work to generate a new test that reaches outside these orders, and would not normally be expected to have time and money to invest in such a non-excludable project. Indeed, not only does doing this work cost them, but the implications of putting these tests in place would ostensibly cost them further, as they go beyond legislated requirements for building and development anywhere in the world. The appearance of private firms getting involved in this work therefore speaks volumes to the growing sense of need for a more fulsome test of sustainable development, adequate to the scale and scope of what the concept promises to provide to the cities that embrace it.

The two snapshot case studies provided here, drawn from interview and document data from a larger research project, are chosen for contrast value. Both architecture and design firms considered here are committed to advancing sustainable development in each project they take on, and to associating this value with their brand. Both have invested private resources into the design and deployment of an internally-generated test of sustainable development, with considerable transparency and publicity about their tool development process and research. The contrast is due to the fact that one of the companies has pursued a test that invites and demands value-based debate, whereas the other falls back on a more simplified promise of clarity and singularity of output, but may not meet the test of value 
in public debate about the reach of sustainable development as an order of worth unto itself. These contrast cases serve to illustrate both the mounting stakes of finding and asserting an adequate test of sustainable development in application, and the different impacts of the polar opposite approaches being offered to settle the terms of the test itself.

While sustainability cannot yet be considered a mainstream value in the design, architecture and construction sectors in cities around the world, a number of firms have established a competitive niche in asserting this as a value. From these firms as well as from the national governments in countries where they operate and from non-government organizations such as the national Green Building Councils, work is taking place to establish a reliable and suitable tool to assess sustainable neighbourhood design and construction. Often, firms work across multiple assessment systems, promoting different ones to different clients depending on contextual factors, or different factors in a given project, or different reputational aspects of different tools. Few, if any, would assert that a single tool works in all client project scenarios. Often, would-be sustainable design firms find themselves frustrated by the sense, when they are working with any given assessment system, that they are "a round peg trying to fit into a square hole" (Transformative Design staff 1 ).

The first case, which we will call Transformative Design, invested two years in the research and design of a new tool which they consider transformative. This full spectrum assessment tool does not provide a single score, value or certification level for a given project, nor does it dictate particular materials or processes. Instead it offers a spectrum of elements that should be considered in any sustainable design, along with the research and evidence to support this inclusion. Says Transformative Design staff 1: "it's not intended to be a recipe, it's intended to be more an approach and an understanding."

The development process for Transformative Design's assessment tool began with a firm-wide visioning session. Staff asked themselves what drove them to do their work each day, and answered, in consensus, that second only to their collective passion for good design was a collective belief "that we can and should meaningfully improve the well-being of communities." Their next step was an intensive research process, led by a national health policy research organization partner. This step assembled over 3000 secondary research sources along with the results of interviews with researchers in the fields of sustainability and well-being, not at all limited to work that was readily transferable to the design profession. From there, the challenge they took up was to devise a framework and measures that they could apply to begin to demonstrate the unique impact that designers could make across a comprehensive set of sectors defined in the research in terms of ambient environmental, public health, demographic and social terms and indicators. The full-spectrum scope was important because they wanted the tool to put them in a position, as a design process manager, to enlarge public dialogue about a project's impact to something more meaningful than they often found to be the case. Well-being was also considered a more manageable pursuit than sustainability:

"We have led downtown plans and neighbourhood plans, community plans but also buildings that are in highly politicized areas. Or infill projects that have a lot of existing interests at odds with each other. I'm sure you have been to all those public open houses where everybody walks in the door ... and they are in defensive position and the conversations tend to be very acrimonious. Very intentionally, this [project] has set out to try and see if we can find some common ground in those conversations whether it's more density, no density, more parking, less parking, heritage conservation or no... If we can get people to act outside of those positions for an instant, and try to find a bigger vision that they can agree upon-so if everybody can agree upon community well-being and something they want to strive for, then what the framework does is it allows you to bring in some manageable conversations." (Transformative Design staff 2)

In addition, these designers found themselves captivated by the potential for change in the political sector of the sustainability assessment spectrum, and recognized the power of isolating the impact of engaging different voices in new ways to a project's ability to deliver on sustainability goals: 
"We really started to look at different social, cultural, environmental, economic domains. And the one that emerged ... was the domain of the political ... and what that means is the acknowledgement of the voices that are participating in the process, and in fact participating in the process has a huge impact on the well-being of the community. As soon as we adopted a definition it really put the finger on community needing to be part of defining the success and the fulfillment... It implied that this was no longer going to be an externally imposed system." (Transformative Design staff 1 )

Also significantly, this design firm recognized that they were not neutral convenors of the dialogue that they saw as necessary. Instead, they recognized that their clients were the actors they most needed to persuade with their efforts toward a new sustainability test. This was a conceptual question of compromise for this group-they needed not to "scare off" their developer clients. It was because of this consideration that "social equity" did not figure explicitly in the assessment framework. Transformative Design staff 2 explains:

"It is really important for us to understand the business case around this because many of our clients, public or private sector, that's what they listen to. So we needed to be able to articulate the connection ... for example, you will see that there is a social equity lens that permeates everything, but we don't have an indicator that points a finger on social equity because we know the developer community is just going to shrug their shoulders, they are not going to even listen anymore, right? There are some elements that from an audience management perspective we need to be a little subversive ... introduce them, but not particularly hit developers on the nose, right, introduce them in different ways."

The Transformative Design staff recognize that while there is considerable readiness to enter into the dialogue that this tool invites, "the maturity of the conversation is only starting to scratch the surface on things like mental health or social well-being, or how do you build the support systems for this community." They have pursued a non-proprietary, open-access approach to the development and publication of this tool throughout and insist that the outcomes they are seeking are better relationships with a wider spectrum of people who are implicated in designing and living more sustainable cities-namely, everyone.

The second design and architecture firm-we will call this company Affirmative Strategies—set for itself a similar scope of work, a similar ambition in entering into a research-based project to define a firm-wide means to assess and report on sustainability performance in a new and bold way. This company took the path of inspiration from the recent spate of climate emergency declarations [46], and the notion of a limited carbon budget for the world as a whole in order to research and assemble its own framework of Whole Life Carbon Assessment. The work is ambitious, benchmarked against other organizations and governments that are leading the world in their ambitions to reduce their carbon emissions at all stages of the life cycle, and oriented toward a target date. Though Affirmative Strategies is involved in many neighbourhood-scale projects, the measurement itself proposed in this tool is limited to single buildings. Affirmative Strategies staff 1 justifies this as incrementalism that ensures the infrastructure will be ready whenever the culture is ready, although it is not ready today. The example given was of the installation of building piping ready to carry recycled water, although there is no agreement to use a water recycling system:

"Do you build the infrastructure first or do you future proof individual buildings as you plan out a master planned community, is the question. In some ways you are building in redundant systems when you take that approach to build buildings first maybe putting in purple piping [for recycled grey water] when there is an upfront cost if they are not planned." (Affirmative Strategies staff 1)

This strategy is argued by Affirmative Strategies staff 1 as a wiser way to innovate toward sustainability transformation, without having to pause technological progress because of the slower 
pace of cultural change and neighbourhood building: "These sites are rarely built out. Because they just can't be, they are just too big." Instead, with their clients, Affirmative Strategies seeks the particular materials, aesthetics, or technologies associated with sustainability that a client is willing to invest in, and aims to change its performance from this starting point: "all of our clients are different. Some are more open to being challenged on the ... sustainable design performance goals. We have clients who are interested in building towers with mass timber so mass timber is looked at as an alternative structural material to concrete or steel ... there are others who are interested in improving the liveability of the units..."

As designers, Affirmative Strategies has confidence in their ability to set and meet ambitious and meaningful sustainable design tests for themselves. In their view, to seek to be tested on the use and readiness of their clients for their buildings would be inappropriate; their buildings are highly sustainable whether their users are able to use them this way or not: "But I don't think it's a failure of the systems themselves, it's failure of the people that are running these buildings to fully understand what they got. These buildings are Cadillacs, they are not Pintos anymore, they are Cadillacs and Ferraris. They are really tuned" (Affirmative Strategies staff 1).

The Whole Life Carbon Assessment Tool proposed by Affirmative Strategies mentions the value of work being conducted by others toward "non-design reduction strategies." These would include the kind of constituency-building work being pursued by Transformative Design. However, they stake their claim in a sustainability test that is all about the technical measurement and management of carbon, within the refined life cycle tool they have developed.

Transformative Design, by contrast, is not so bothered by the complexity of the political domain of "non-design reduction strategies." Their test lacks the bottom line security and precision of a zero carbon strategy, yet recognizes value in the process of building trust with clients by engaging in conversation about these strategies. This, although they may disagree: "What we are finding is that the process may still be complex but at least the outcomes are getting closer to something that is meaningful and the relationship, it gets closer to a relationship of trust because you can back it into something that people can start to understand the process and try and get language that everybody can use."

\section{Discussion and Conclusions}

For sustainable cities to move into the realm of lived experience, new heterogenous tests of the experiential as well as technical meaning of sustainable cities are needed. The fact that even private actors, living predominantly in the market, projective, or industrial orders of worth, facing significant costs and indeterminate benefits of mounting a test of a new order, are engaging in the creation of new tests, tailor-made to gauge true urban sustainability progress, is proof of this need. The present moment of sustainable urban development can be considered in this way as a moment rich with the proliferation of new proposed tests of urban sustainability. It is as yet unclear which tests will succeed, and which may fail, to offer justification for the status of sustainability as an order of worth for the world held in common.

Urban critics have offered plenty of denunciations of the prospect of finding within sustainable urban developments what is needed for a legitimate reordering of worth in the city. Within the examples of urban design strategies used in model sustainable neighbourhoods, no necessary connection exists with the imputed outcomes of ecological, economic, and social health and harmony. Others note from a political science perspective that while cities may resist mainstream unsustainable trends, their valiant efforts are trumped by countervailing nation state politics. Others, from a perspective of social and community studies, have noted that even if we adequately value all of our urban diversity, and the various commoning strategies that work within this diversity, the question remains about the use to which we will put it. The suite of initiatives typically included within the realm of model sustainable development in today's cities, reaches far beyond energy and carbon efficiency to include components from bikes to books, shared kitchens and gardens, cars and "meet-ups." Within this 
are certain topics of identity, social mixing and class that are rarely if ever part of the package of justifications advanced in public for sustainable development. This means that there are people who rarely or never see themselves as part of the sustainable city ideal. Advocates for those people remind us that, as often as questions of equal rights and non-discrimination against people based upon class, gender, sexuality, race, indigeneity or immigration status have been voiced, they have not been settled [47-50]. Sustainable city transformation work, as Jeffrey et al. [50] put it, "has its own walls" and exclusionary practices.

Stated differently, as some of the critical scholars of sustainable neighbourhood transformation have witnessed, when this work is conducted in cities without adequate tests, it assumes the same political dynamics as exist in any other contemporary urban development process. A label, certification, or star assessment in this case does not introduce a new way of justifying the work as sustainable but sticks to the same understanding and replicates power and information imbalances, gaps in representation of key neighbourhood elements, and the privileging of private property and enterprise. Should a suitable new test be found and implemented, however, the institutions holding power over the city would have obligations to explain themselves differently in order to remain legitimate and authentic in the public eye. The ways in which urbanites could begin to see themselves living, well, in the city could change, in a publicly justifiable way, that would open up arguments about new kinds of social value and worth. This is not to say that a single test could settle, once and for all, the meaning and key components of an ideal sustainable city. It is to say that a better test could introduce into the obligations of urban politics a new set of objects and elements that would demand adequate discussion and treatment for any urban project to be judged publicly worthy.

While it is often used as a stand-in for a hidden justification of market, projective, or other orders of worth, sustainable development also continues to be articulated as part of a conception of just outcomes as if it holds weight in this way, in its own right. If sustainability is to hold meaning as a social frame of justice-that is, as a guide for conditions by which people can put their lives in normative order, as a way of thinking that encourages living well-then we need a moral or justice-oriented way of thinking about sustainable cities and sustainable lifestyles [14]. If people are publicly advancing arguments, and if these arguments are meeting certain tests put to them, then sustainability holds potential to serve as the awakening of a different moral ordering of cultures, a new way of understanding value and status, an alternative grip on the world and what it means to work and live within it. Bits and pieces of promise for this future sustainable city abound, in the variety of tests heaped at the feet of cities, model sustainable neighbourhoods, their occupants, and their champions. They surround constructions of the common good, the way public arguments are waged, and the struggle over articulating and justifying the truth in particular situations. Within all of this is the substance of a larger social question, still inchoate, about the purpose of our cities at this moment of dire crises of injustice and unsustainability.

The enduring pursuit of sustainable development within the many and very real worlds of cities is a sign of hope in the prospect of social transformation. At the same time, this source of hope is not reason for celebration of the results so far of efforts in the name of sustainable development. The urban neighbourhood is a window into many other worldly domains, including both human and non-human communities, and serves diverse individual and social needs, in a range of forms and orientations of membership and attachment. Many sustainable urban neighbourhood projects may have met some goals attributed to and assessed for sustainable development, such as levels of housing density that are appropriate for human sociability, connections between living, working and mobility alternatives to private cars, alternatives to single use zones, alternatives to exclusionary regime politics and the promotion of private property against all other goals. On balance, however, model sustainable neighbourhoods, and the ways in which their results are tested for sustainable development results, do not currently add up to the aspirations that would be fit to justify sustainability as a new widespread order of worth. Better tests, and better recognition of the many, diverse, valuable ways in which people may engage in generating and living in sustainable neighbourhoods and cities, are still needed. As a set of complex social processes, habits, and beliefs, urban qualities and boundaries, empowerment and 
participation in decision-making, and community-building requires careful analysis, rather than either romantic attachment or cynical rejection.

A stream of scholarship, drawing from the pragmatic tradition, seeks a middle way between transformative and affirmative strategies in approaches that incorporate critique and action for social change [51-54]. At the same time, it recognizes the risks of middle ways. Pragmatic efforts to advance our thinking and our actions at the neighbourhood scale can better reveal the opportunities to work for justice and sustainability in contemporary cities. At the same time, this work can also lower our sights for the possibility spaces that may demand different scales of action. The move proposed here is to find a line between critique and co-optation that social change motivated scholarship can follow. Perry and Atherton [54] propose a model in which researcher-critics engaged co-productively with institutions, via a tactic "to work through an affirmative mode, whilst remoulding the conditions for transformation to take place." They point out the "value of co-production in supporting collaboration on the challenges, opportunities and actions for existing institutions to develop 'more just' approaches to environmental policy and governance" [54]. They acknowledge as a drawback to this approach that it lacks a clear test of value and worthiness. They do not consider this to be a fatal flaw in the approach, but in view of the argument presented here, we should take it very seriously. We should heed the warning of Boltanski and Chiapello [24], in their path-breaking work on the transformation of capitalism in order to survive the growing critiques of the 1990s, to generate a "new spirit" of capitalism, that the satisfaction that is obtained from framing and articulating critique is, in itself, dangerous. It is dangerous because when we satisfy ourselves with the construction of critiques, we are not spending our time confronting the contradictions that confound the ways in which we justify our own worlds and actions. It is the work of confronting these contradictions, and mounting tests in order to force a reconciliation, that is essential to the continuous project of internalizing the pursuit of justice, in culture and in context.

The urge to justify sustainability as a new order of worth in the mix of competing urban priorities is the flip side of a rejection of these past mistakes in social organization, and an impulse to generate something new, with new potential to respond effectively to the threats to existing ways of valuing priorities. Importantly, visions of what is worthy and valuable within the sustainable city are aspirational visions. They are important as such, not only as ways to address other important technical questions in urban development, such as density, urban form, mobility, economies and community dynamics. They represent our best aggregation of our common understandings of reference points against which the success of efforts to create sustainable cities ought to be judged in a new urban ordering of the world. Taking the thrust of the multiple justifications of the common world of the city into account, we can also more clearly recognize what about these justifications is and is not so new, what they fail to account for, and the nature of the tests that any work toward sustainable cities must pass in order to add up to the kind of aspiration that is worth working for and talking about.

Funding: This research project was funded by SSHRC 2014 Insight Grant 435-2014-0465.

Acknowledgments: This research project, Ecourbanism Worldwide, was conducted via an ethical research protocol, 2014s0214, certified by Simon Fraser University Department of Research Ethics. The author gratefully acknowledges the assistance of Annika Airas in preparing the data used in this article.

Conflicts of Interest: The author declares no conflict of interest.

\section{References}

1. Torgerson, D. The Uncertain Quest for Sustainability: Public Discourse and the Politics of Environmentalism; Springer: Berlin/Heidelberg, Germany, 1995; pp. 3-20.

2. Barber, B. If Mayors Ruled the World: Dysfunctional Nations; Rising Cities Yale University Press: New Haven, CT, USA, 2013.

3. C40 Cities. Case Study: Climate Action in Major Cities, C40 Cities Baseline and Opportunities. Available online: http://www.c40.org/case_studies/climate-action-in-major-cities-c40-cities-baseline-andopportunities (accessed on 18 August 2019). 
4. Ecodistricts. The Ecodistricts Protocol v1.3. Portland, OR. Available online: http://www.ecodistricts.org (accessed on 29 May 2019).

5. Future Earth and the Earth League. $10 \mathrm{New}$ Insights in Climate Science 2018. Available online: https: //briefs.futureearth.org/wp-content/uploads/2018/12/10-New-Insights-in-Climate-Science-2018-online.pdf (accessed on 1 April 2020).

6. Williamson, K.; Satre-Meloy, A.; Velasco, K.; Green, K. Climate Change Needs Behaviour Change: Making the Case for Behavioural Solutions to Reduce Global Warming; Rare: Arlington, VA, USA, 2018; Available online: https://rare.org/wp-content/uploads/2019/02/2018-CCNBC-Report.pdf (accessed on 1 April 2020).

7. FAO; IFAD; UNICEF; WFP; WHO. The State of Food Security and Nutrition in the World 2018. Building Climate Resilience for Food Security and Nutrition. Available online: http://www.fao.org/3/i9553en/i9553en.pdf (accessed on 1 April 2020).

8. Organisation for Economic Co-operation and Development. Implementing the Paris Agreement: Remaining Challenges and the Role of the OECD. Available online: http://www.oecd.org/mcm-2018/documents/C-MIN2018-12-EN.pdf (accessed on 1 April 2020).

9. United Nations Department of Economic and Social Affairs. The Sustainable Development Goals Report 2018. Available online: https://www.un.org/development/desa/publications/the-sustainable-developmentgoals-report-2018.html (accessed on 4 June 2020).

10. Holden, M.; Li, C.; Molina, A. The emergence and spread of ecourban neighbourhoods around the world. Sustainability 2015, 7, 11418-11437. [CrossRef]

11. About, C.; Doussard, C.; Holden, M. (re)Penser la Ville du XXIe Siècle: 20 Ans D'écoquartiers dans le Monde; Dunod: Paris, France, 2019.

12. Sharifi, A. From garden city to eco-urbanism: The quest for sustainable neighborhood development. Sustain. Cities Soc. 2016, 20, 1-16. [CrossRef]

13. Sharifi, A.; Murayama, A. A critical review of seven selected neighborhood sustainability assessment tools. Environ. Impact Assess. Rev. 2013, 38, 73-87. [CrossRef]

14. Holden, M. Pragmatic Justifications for the Sustainable City; Earthscan: London, UK, 2017.

15. Breviglieri, M.; Diaz, P.; Nardacchione, G. L'expérience latino-américaine de la sociologie pragmatique francophone. Elargissement d'un horizon d'analyse? SociologieS 2017. Available online: https://journals. openedition.org/sociologies/6174 (accessed on 1 April 2020).

16. Boissonade, J. Le développement durable face à ses épreuves. Espaces Et Sociétés 2011, 147, 57. [CrossRef]

17. Holden, M.; Scerri, A. Justification, compromise and test: Developing a pragmatic sociology of critique to understand the outcomes of urban redevelopment. Plan. Theory 2014, 14, 360-383. [CrossRef]

18. Gilman, S.L.; Deleuze, G.; Guattari, F.; Massumi, B. A Thousand plateaus: Capitalism and schizophrenia. J. Interdiscip. Hist. 1989, 19, 657. [CrossRef]

19. Latour, B. We Have Never Been Modern; Harvard University Press: Cambridge, MA, USA, 1993.

20. Scott, A.; Gane, M.; Webster, A.; Banks, J.; Silverman, D.; Denora, T.; Bernardes, J.; Pahl, R.; Bowler, I.; Thomas, J.; et al. Book Reviews: Knowledge, Ideology and Discourse: A Sociological Perspective; Routledge: London, UK, 1993; Available online: https://journals.sagepub.com/doi/10.1111/j.1467-954X.1993.tb02958.x (accessed on 4 June 2020).

21. Barbier, R. Une Cité de L'écologie. Mémoire de DEA; EHESS: Paris, France, 1992.

22. Lafaye, C.; Thévenot, L.; Cloutier, C.; Gond, J.-P.; Leca, B. An ecological justification? Conflicts in the development of nature. Res. Soc. Org. 2017, 52, 273-300. [CrossRef]

23. Stark, D. For What it's worth. In Justification, Evaluation and Critique in the Study of Organizations; Emerald: West Yorkshire, UK, 2017; Volume 52, pp. 383-397.

24. Boltanski, L.; Chiapello, E. The new spirit of capitalism. Int. J. Politics Cult. Soc. 2005, 18, 161-188. [CrossRef]

25. Latour, B. Moderniser ou écologiser, à la recherche de la « septième » cité. Ecol. Polit. 1995, 13, 5-27. (In French)

26. Zuindeau, B. La durabilité: Essai de positionnement épistémologique du concept. In Développement et Territoires; Zuindeau, B., Ed.; Presses Universitaires du Septentrion: Villeneuve d'Ascq, France, 2000.

27. Thévenot, L.; Moody, M.; Lafaye, C. 9-Forms of Valuing Nature: Arguments and Modes of Justification in French and American Environmental Disputes; Cambridge University Press: Cambridge, UK, 2000; pp. 229-272.

28. Godard, O. De la pluralité des orders—Les problèmes d'environnement et de développement durable à la lumière de la théorie de la justification. Géographie Économie Société 2004, 6, 303-330. (In French) [CrossRef] 
29. Claeys-Mekdade, C. Le Lien Politique a L'épreuve de L'environnement. Expériences Camarguaises; PIE Peter Lang: Brussels, Belgium, 2003.

30. Centemeri, L. Reframing Problems of incommensurability in environmental conflicts through pragmatic sociology: From value pluralism to the plurality of modes of engagement with the environment. Environ. Values 2015, 24, 299-320. [CrossRef]

31. Boissonade, J. Une approche pragmatiste dans la critique du développement durable. In La Ville Durable Controversée: Les Dynamiques Urbaines dans le Mouvement Critique; Boissonade, J., Ed.; PETRA: Paris, France, 2015; pp. 41-72. (In French)

32. Boissonade, J.; Hackenberg, K. La Nature contre la culture? De la controverse écologique à la mise en ordre du milieu local. Développement Durable et Territoires 2011, 2, 2. Available online: http://developpementdurable. revues.org/8935 (accessed on 1 April 2020).

33. Stark, D. For what it's worth. In Justification, Evaluation and critique in the study of organizations: Contributions from French pragmatist sociology. Res. Soc. Org. 2017, 52, 383-397.

34. Fainstein, S.S. The Just City; Cornell University Press: Ithaca, NY, USA, 2011.

35. Lejeune, C.; Villalba, B. La Justification Durable Comme Extension du Productivisme. In Sociologie des Approches Critiques du Développement Et de la Ville Durables; Boissonade, J., Hackenberg, K., Eds.; PETRA: Paris, France, 2015; pp. 255-285.

36. Blok, A. Pragmatic sociology as political ecology. Eur. J. Soc. Theory 2013, 16, 492-510. [CrossRef]

37. Blok, A. Greening Cosmopolitan urbanism? On the transnational mobility of low-carbon formats in Northern European and East Asian Cities. Environ. Plan. A Econ. Space 2012, 44, 2327-2343. [CrossRef]

38. Montgomery, A.F. Different futures for different neighborhoods: The sustainability fix in Detroit. Ethnography 2015, 16, 523-555. [CrossRef]

39. Pattaroni, L. Le nouvel esprit de la ville. Mouvements 2011, 65, 43. [CrossRef]

40. Curran, W.; Hamilton, T. Just green enough: Contesting environmental gentrification in Greenpoint, Brooklyn. Local Environ. 2012, 17, 1027-1042. [CrossRef]

41. Garde, A. Sustainable by design? Insights from U.S. LEED-ND pilot projects. J. Am. Plan. Assoc. 2009, 75, 424-440. [CrossRef]

42. Szibbo, N.A. Assessing Neighborhood Livability: Evidence from LEED®for Neighborhood Development and New Urbanist Communities. Articulo 2015, 14. [CrossRef]

43. Chastenet, C.A.-D.; Belziti, D.; Bessis, B.; Faucheux, F.; Le Sceller, T.; Monaco, F.-X.; Pech, P. The French eco-neighbourhood evaluation model: Contributions to sustainable city making and to the evolution of urban practices. J. Environ. Manag. 2016, 176, 69-78. [CrossRef] [PubMed]

44. Talen, E.; Allen, E.; Bosse, A.; Ahmann, J.; Koschinsky, J.; Wentz, E.; Anselin, L. LEED-ND as an urban metric. Landsc. Urban Plan. 2013, 119, 20-34. [CrossRef]

45. Holden, M.; Li, C.; Molina, A.; Sturgeon, D. Crafting new urban assemblages and steering neighborhood transition: Actors and roles in ecourban neighborhood development. Articulo 2015, 14. [CrossRef]

46. Ripple, W.J.; Wolf, C.; Newsome, T.M.; Barnard, P.; Moomaw, W.R. World scientists' warning of a climate emergency. Bioscience 2019, 70, 8-12. [CrossRef]

47. Joseph, M. Against the Romance of Community; University of Minnesota Press: Minneapolis, MN, USA, 2002.

48. Griffin, T. Defining the Just City Beyond Black and White. In The Just City Essays. 26Visions for Urban Equity, Inclusion and Opportunity; Griffin, T., Cohen, A., Maddox, D., Eds.; J Max Bond Center on Design: New York, NY, USA; Spitzer School of Architecture: New York, NY, USA; City College of New York: New York, NY, USA; Next City: Philadelphia, PA, USA; The Nature of Cities: New York, NY, USA, 2015; Volume 1, pp. 6-9.

49. Lokko, L. In It Together. In The Just City Essays. 26 Visions for Urban Equity, Inclusion and Opportunity; Griffin, T., Cohen, A., Maddox, D., Eds.; J Max Bond Center on Design: New York, NY, USA; Spitzer School of Architecture: New York, NY, USA; City College of New York: New York, NY, USA; Next City: Philadelphia, PA, USA; The Nature of Cities: New York, NY, USA, 2015; Volume 1, pp. 10-14.

50. Jeffrey, A.; McFarlane, C.; Vasudevan, A. Rethinking Enclosure: Space, Subjectivity and The Commons. Antipode 2011, 44, 1247-1267. [CrossRef]

51. Fraser, N.; Honneth, A. Redistribution or Recognition? A Political-Philosophical Exchange; Golb, J., Ingram, J., Wilke, C., Eds.; Verso: London, UK, 2003. 
52. Conti, A. Metropolitan Proletarian Research. Available online: www.ecn.org/valkohaalarit/english/conti.htm (accessed on 1 April 2020).

53. Boltanski, L. On Critique. A Sociology of Emancipation; Polity: Cambridge, UK, 2011.

54. Perry, B.; Atherton, M. Beyond critique: The value of co-production in realising just cities? Local Environ. 2017, 22, 36-51. [CrossRef] 